\title{
Investigación en enseñanza de las ciencias en Colombia: estudio desde sus cosificaciones*
}

\section{Milena Alcocer Tocora}

https://orcid.org/0000-0002-4840-0551 Universidad de Los Andes, Colombia mr.alcocer1o@uniandes.edu.co

\section{Carola Hernández Hernández}

https://orcid.org/00oo-0002-4062-9140 Universidad de Los Andes, Colombia c-hernan@uniandes.edu.co

\section{Resumen}

Los productos de investigación publicados y socializados por la comunidad cientifica son más que objetos materiales, son cosificaciones que representan su identidad, sus significados y su práctica. Este artículo presenta un análisis de la comunidad de investigadores en enseñanza de las ciencias en Colombia desde sus cosificaciones. El estudio se desarrolló con base en un enfoque cualitativo y desde una perspectiva crítica y hermenéutica. Se revisaron los productos de investigación reportados en la plataforma ScienTI de Colciencias, así como las memorias publicadas por los dos principales eventos nacionales especializados en el campo durante la última década. Se identificó que la práctica de la comunidad gira en torno a intereses que se relacionan con dos posturas epistemológicas: la educación en ciencias y la didáctica de las ciencias. Estas perspectivas orientan epistemológicamente la producción de los investigadores y determinan las relaciones entre la teoría y la práctica pedagógica. El análisis también evidenció la urgencia de ampliar los diálogos entre los miembros de la comunidad que permitan llegar a acuerdos concretos frente a las necesidades del campo de investigación en Colombia.

\section{Palabras clave (Fuente: tesauro de la Unesco)}

Enseñanza de las ciencias; comunidad científica; prácticas pedagógicas; comunidad de práctica; cultura científica.

\footnotetext{
* Artículo derivado de la tesis de doctorado titulada: "Perspectivas socio-culturales de ciencia y aprendizaje: Aportes en la formación y en las prácticas pedagógicas de profesores en ejercicio". Doctorado en Educación, Universidad de los Andes, 2018.
}

Recepción: 15/04/2019 | Envío a pares: 23/10/2019 | Aceptación por pares: 03/02/2020 | Aprobación: 13/02/2020 


\title{
Research in Science Teaching in Colombia: A Study from its Reifications*
}

\begin{abstract}
Research products published and disseminated by the scientific community are more than material objects: they are reifications that represent its identity, meanings, and practice. This article presents an analysis of the community of science teaching researchers in Colombia based on its reifications. The study is conducted with a qualitative approach and from a critical and hermeneutical perspective. The research products reported on the Colciencias ScienTI platform, as well as the proceedings of the two major national events in the field held in the last decade, are reviewed. It was identified that the practice of this community revolves around interests related to two epistemological positions: science education and science didactics, which guide the production of researchers and determine the relationships between theory and pedagogical practice. The analysis also pinpoints the need to broaden the dialogues among the members of the community to reach concrete agreements that benefit research in Colombia.
\end{abstract}

\section{Keywords (Source: Unesco Thesaurus)}

Science education; scientific communities; Scientists; pedagogy practices; community of practice; scientific culture.

\footnotetext{
* $\quad$ Article derived from the doctoral dissertation entitled "Perspectivas socio-culturales de ciencia y aprendizaje: aportes en la formación y en las prácticas pedagógicas de profesores en ejercicio" Ph.D. in Education, Universidad de los Andes, 2018.
} 


\section{Pesquisa em ensino das Ciências na Colômbia: estudo a partir de suas coisificações*}

\section{Resumo}

Os produtos de pesquisa publicados e socializados pela comunidade científica são mais do que objetos materiais: são coisificações que representam sua identidade, seus significados e sua prática. Este artigo apresenta uma análise da comunidade de pesquisadores em ensino de Ciências na Colômbia a partir de suas coisificações. O estudo foi desenvolvido com base numa abordagem qualitativa e sob uma perspectiva crítica e hermenêutica. Foram revisados os produtos de pesquisa relatados na plataforma ScienTI do Departamento de Administração de Ciência e Tecnologia (Colciencias), bem como as memórias publicadas pelos dois principais eventos nacionais especializados no campo durante a última década. Foi identificado que a prática da comunidade gira em torno de interesses que estão relacionados com dois posicionamentos epistemológicos: a educação em Ciências e a didática em Ciências. Essas perspectivas orientam epistemologicamente a produção dos pesquisadores e determinam as relações entre a teoria e a prática pedagógica. A análise também evidenciou a urgência de ampliar os diálogos entre os membros da comunidade que permitam chegar a acordos concretos ante as necessidades do campo de pesquisa na Colômbia.

\section{Palavras-chave (Fonte: tesauro da Unesco)}

Educação em ciências; comunidade científica; cientista; práticas pedagógicas; comunidade de prática; cultura científica.

Artigo derivado da tese de doutorado em Educação intitulada "Perspectivas socio-culturales de ciencia y aprendizaje: aportes en la formación y en las prácticas pedagógicas de profesores en ejercicio" "Perspectivas socioculturais de Ciência e aprendizagem: contribuições para a formação e para as práticas pedagógicas de professores em exercício"), realizado na Universidad de los Andes, Colômbia, em 2018. 


\section{Introducción}

El campo de investigación en enseñanza de las ciencias tiene una amplia trayectoria en el escenario de la educación internacional. Para los años 80 se evidenció el incremento y la formalización de investigaciones dentro de las universidades en diferentes partes del mundo a través de un aumento en el número de grupos de investigación en el área (Gil, Carrascosa y Martínez, 1999). De acuerdo con López (2006), para esa época predominaban investigaciones guiadas por las visiones anglosajona y francesa que se caracterizaban por poseer una tendencia constructivista. La postura anglosajona planteó proyectos curriculares para la enseñanza de las ciencias orientados a la transformación de la enseñanza tradicional (Porlán, 1985). Por su parte, la postura francesa estableció como finalidad profundizar en lo que se relaciona directamente con la comprensión del proceso de enseñanza y aprendizaje (Soussan, 2003; Viennot, 1997) a través la cotidianidad de las aulas, estableciendo las relaciones entre quien aprende, el contenido y quien enseña.

Para el caso de Colombia, este campo de investigación se consolidó desde los años 90 con una gran influencia de la postura francesa, es decir, de la didáctica de las ciencias experimentales y las matemáticas. La literatura reporta más de 20 años de producciones que dan la idea de una comunidad académica sólida y que aporta respuestas a los desafíos que implica la enseñanza de las ciencias en el país. También se han realizado estudios sobre la dinámica del campo y se identifica que la mayoría de ellos se concentran en la descripción de las líneas de investigación que se imponen en el escenario académico (Badillo, Torres y Miranda, 2002; Hernández, 2001; Vasco, 1993; Zambrano, Salazar, Candela y Villa, 2013; Zambrano, 2015; Zambrano, Viáfara y Marín, 2008).

Lo anterior proporciona información importante sobre los enfoques y los escenarios de acción que aborda la comunidad, pero no profundiza en lo que la identifica ni en la práctica que la caracteriza. El reconocimiento de la identidad y de la práctica de una comunidad favorece su posicionamiento, potencia las actividades que desarrolla y orienta la perspectiva de trabajo hacia el futuro. De acuerdo con Wenger (1998), existe una profunda conexión entre estos dos aspectos, pues la práctica determina la conformación de una comunidad y a su vez posibilita la construcción de la identidad. Es decir, las relaciones entre identidad y práctica son, en el contexto real, una dualidad que por momentos se hace difícil de diferenciar.

Una forma de identificar esta dualidad dentro de una comunidad es analizando los productos abstractos y físicos que ha desarrollado a través de su existencia. Según Wenger, los productos desarrollados por una comunidad son resultado de la cosificación, que es: "el proceso de dar forma a nuestra experiencia produciendo objetos que plasman dicha experiencia en una 'cosa'”, y ello es así pues "cualquier comunidad de práctica produce abstracciones, instrumentos, símbolos, relatos, términos y conceptos que cosifican algo de esa práctica en una forma solidificada" (1998, p. 84). Así, se puede considerar que los productos de investigación publicados y socializados por la comunidad científica son cosificaciones de su práctica y no objetos o materiales inertes. Por el contrario, estos son entendidos como una proyección individual y colectiva de los significados que construye la comunidad y da forma a la experiencia de hacer parte de ella. Es decir, reflejan lo que es la práctica propia de la comunidad, comunican sus significados y también constituyen una forma de pensar.

Entonces, la cosificación y la participación no pueden pensarse por separado y se encuentran relacionadas directamente con la práctica. El análisis de la existencia de un producto de la cosificación permite reconocer lo que se cosifica y a la vez cobra sentido dentro de la participación por medio de su uso. En este orden de ideas, estos dos aspectos deben sostener una relación equilibrada. Cuando una de las dos predomina pueden presentarse problemas con la continuidad del significado y, por consiguien- 
te, con la práctica que desarrolla la comunidad. Por ejemplo, si la balanza se inclina hacia la participación, se pueden perder los significados producidos por la comunidad. De otro lado, si lo que prevalece es la cosificación, no se da espacio a un experiencia compartida y a una negociación activa de significados (Wenger, 1998). Por lo tanto, los productos de investigación y los acuerdos que se dan como resultado de la participación se convierten en una gran fuente de información sobre la identidad y la práctica de una comunidad.

Por ello, este estudio tiene como propósito principal realizar una descripción de la identidad, de la práctica y de la participación que caracteriza la comunidad de investigadores en enseñanza de las ciencias en Colombia en la década 2006-20016. Antes de mostrar el diseño metodológico y los resultados de este estudio, presentaremos un breve recorrido histórico por la consolidación del campo de investigación en enseñanza de las ciencias en Colombia. Este recorrido favorece un primer acercamiento a la comunidad a la luz de sus motivaciones, protagonistas y líneas de trabajo a través del tiempo.

\section{Contexto histórico de la consolidación del campo de investigación en Colombia}

Durante los años 70 y 80 el proceso de consolidación de la comunidad interesada en la investigación en la enseñanza y aprendizaje de las ciencias está relacionado con tendencias nacionales, como el movimiento pedagógico nacional, que favorecieron el empoderamiento del profesor frente a su quehacer profesional a través de la investigación educativa (Hernández, 2001). Este movimiento fue liderado por los grupos: "Federici" de la Universidad Nacional de Colombia y "Prácticas pedagógicas" de la Universidad Pedagógica Nacional (Echeverri, 2010) y se convirtió en una nueva corriente de pensamiento.

Su propósito central fue promover desde la base un nuevo rol para los profesores en el sistema educativo. Desde esta perspectiva, el profesor ya no cumpliría un rol pasivo en su quehacer profesional $y$, por el contario, se caracterizaría por ser un importante actor dentro del sistema educativo a través de pensar en las formas más adecuadas de enseñar su saber usando la investigación (Elliott, 1993; Stenhouse, 1987). Esto favoreció la consolidación de la investigación en la enseñanza de varias disciplinas, entre ellas, las ciencias, y fue así como la investigación educativa empezó a cumplir un papel importante en la producción de nuevo conocimiento en este campo. La documentación formal del proceso de consolidación del campo de investigación empezó en los años go.

En 1993 Carlos Vasco argumentó que las primeras líneas de investigación en el país se articularon alrededor de cuatro aspectos: 1) las perspectivas del aprendizaje de los conceptos y el cambio conceptual, 2) la enseñanza desde el desarrollo del niño, 3) los factores diferenciales en el aprendizaje (estilos de aprendizaje y actividades psicosociales para el trabajo en grupo) y 4) la resolución de problemas aplicados al trabajo de aula. Adicionalmente, se logró evidenciar que las líneas mencionadas emergieron como resultado del trabajo realizado por profesores investigadores dentro de las universidades y sus programas de formación de docentes.

A partir de allí, la década de 1990 constituye un periodo de tiempo muy importante para esta comunidad, porque seidentifica un aumento en el número de publicaciones y la creación de nuevos programas de formación posgradual de profesores que posibilitaron investigaciones y dieron pie al fortalecimiento de los grupos de investigación de la época. En 2001, Carlos Hernández, profesor de la Universidad Nacional, publicó un estudio que presenta un primer acercamiento al estado del conocimiento en el campo de investigación de la enseñanza de las ciencias. El autor tomó como referente principal los proyectos de investigación apoyados por Colciencias en la década entre 1988 y 1998, identificó la importancia de los estudios realizados hasta ese momento en la consolidación de una comunidad académica nacio- 
nal y presentó un análisis de las principales líneas de investigación. Varias de estas líneas estuvieron articuladas con el primer doctorado en educación del país, ofrecido por cinco universidades públicas (Nacional de Colombia, Industrial de Santander, del Valle, Pedagógica Nacional y de Antioquia). Esto fue un aporte importante para la consolidación de la comunidad en el escenario nacional.

En este mismo estudio se evidenciaron tres puntos de articulación entre las investigaciones realizadas: la preocupación por el cambio conceptual, el desarrollo de propuestas fundamentadas en el constructivismo y los trabajos orientados por el aprendizaje significativo. Sin embargo, desde la perspectiva del autor, los intereses y las estrategias de trabajo en diversos grupos fueron diferentes: 1) se continuó tratando de caracterizar ideas previas, preconceptos y preteorías; 2 ) se estudiaron métodos de trabajo en el aula con relación al constructivismo y al aprendizaje significativo; 3) se desarrolló fundamentación teórica sobre precisiones conceptuales alrededor del aprendizaje de conceptos (esto se asoció con epistemología e historia de las ciencias); 4) se exploraron estrategias metacognitivas sobre las formas de aprender (esto es útil no solo para los docentes, sino también para los estudiantes); 5) se realizaron trabajos sobre las creencias y el quehacer como educador de los docentes; 6) se estudió la apropiación de la cultura científica en la formación integral de los estudiantes; 7) se abordó la relación entre la tecnología y el aprendizaje de las ciencias; 8) se analizó la relación entre la organización y la autorregulación del trabajo pedagógico; 9) se establecieron diferencias entre situaciones escolares, contextos culturales, formas de organizar contenidos y estrategias pedagógicas (Hernández, 2001).

Adicionalmente, a nivel de educación superior, en 2003 se publicó el texto Educación y formación del pensamiento científico: Cátedra ICFES Agustín Nieto Caballero (Zambrano, 2003), que presentó el estado de la educación en ciencias naturales a este nivel e identificó las principales líneas de investigación en los ámbitos internacional y nacional. Las líneas identificadas fueron: 1) concepciones alternativas; 2) el cambio conceptual en ciencias; 3 ) dificultades de aprendizaje; 4) el pensamiento y la acción del docente; 5) la resolución de problemas; 6) la evaluación; 7) la construcción del conocimiento escolar a partir del conocimiento del estudiante; 8) la relación entre aprendizaje, evaluación y cambio conceptual a partir de la historia y la epistemología de las ciencias; 9) el laboratorio como campo de investigación emergente; 10) la enseñanza de los conceptos científicos a través de tiras cómicas, y 11) la influencia del contexto cultural en el aprendizaje del estudiante.

En 2004, el Ministerio de Educación Nacional (MEN) presentó los estándares básicos de ciencias naturales y sociales con el objetivo de orientar la atención de las problemáticas planteadas en las investigaciones y asi mejorar la calidad de la educación en ciencias en el país. Estos estándares establecieron una postura epistemológica para la enseñanza de las ciencias y presentaron una serie de competencias y habilidades básicas para aprenderlas de acuerdo con las exigencias del mundo contemporáneo (MEN, 2004). Dicho documento se desarrolló dentro del marco del plan nacional de desarrollo de la época y fue coordinado por la Asociación de Facultades de Educación y centros de investigación en educación, como el CIFE, de la Universidad de los Andes. Además, contó con el apoyo de maestros y miembros de la comunidad educativa en general. Este trabajo evidenció la participación activa de la comunidad académica en el desarrollo de políticas públicas para la transformación de la educación en el país.

En 2015, Zambrano y su grupo de trabajo en la Universidad del Valle identificaron para el periodo comprendido entre los años 2000 y 2011 las principales líneas de investigación en educación en ciencias en el país y presentaron un acercamiento al estatuto epistemológico del campo. En este trabajo, el estatuto epistemológico fue entendido como el reconocimiento del campo en términos de conocer: quién investiga, qué se investiga, cómo se investiga, 
qué resultados se obtienen y qué significan estos aspectos para el campo de estudios. Sin embargo, los documentos que reportan los resultados obtenidos no profundizan en todos estos aspectos. El estudio se enfocó en identificar y caracterizar las líneas de investigación que dinamizan el campo de investigación en Colombia y también se presentó el nombre de las instituciones y de los principales investigadores que se encuentran liderando cada línea en el país (Zambrano et al., 2013; Zambrano, 2015).

Estas líneas fueron clasificadas de la siguiente manera: 1) relación del conocimiento científico y el conocimiento común; 2) enseñanza, aprendizaje y evaluación: metacognición, cambio conceptual, resolución de problemas e historia de las ciencias; 3) relación entre teoría y práctica en las ciencias experimentales a través del laboratorio escolar; 4) nuevas tecnologías de la informática y la comunicación y su relación con la educación en ciencias naturales, inteligencia artificial y procesos de razonamiento; 5) desarrollo curricular en ciencias naturales; 6) contextos culturales, educación ambiental, educación en ciencias en ambientes no convencionales, y 7) conocimiento, pensamiento y formación del maestro.

Adicionalmente, este autor identificó que las reformas curriculares realizadas en Colombia son la base del contenido y de la práctica de la educación en ciencias en las instituciones educativas. En su análisis identifica que aún existen rupturas entre las propuestas pedagógicas basadas en la investigación en educación en ciencias y las acciones llevadas a cabo por los profesores en el aula. Al respecto, Zambrano y su grupo plantean que la comunidad de investigadores en educación en ciencias en Colombia ha aumentado su interés en superar la ruptura entre la teoría y la práctica, pero reconoce que aún falta mucho camino por recorrer para lograrlo. Identifican en los escenarios de formación posgradual (especializaciones, maestrías y doctorados) una oportunidad para que las nuevas generaciones de docentes continúen su desarrollo profesional y encuentren alternativas a través de procesos de in- vestigación sobre la práctica. Estos procesos contribuyen a cerrar las brechas que se mantienen desde hace varias décadas (Zambrano, 2015).

Una evidencia importante de la falta de coherencia entre la teoría y la práctica, como problema recurrente, es que la educación en ciencias en Colombia ha sido fuertemente cuestionada en los últimos años debido a los bajos resultados obtenidos por los estudiantes en las pruebas Saber 11 y PISA. Esto llevó a buscar comprender el problema de fondo por parte de otros actores externos a este campo, por lo que se han realizado diferentes análisis que evidencian problemas complejos en el sistema educativo y en la formación de profesores que repercuten en las prácticas pedagógicas (Barrera, Maldonado y Rodríguez, 2012; ICFES, 2013; MEN, 2012).

Desde esta perspectiva, el estudio de las prácticas pedagógicas se configura como un escenario importante para encontrar la respuesta a los problemas identificados anteriormente. Al respecto, investigaciones internacionales han reportado relaciones directas entre los países que han logrado integrar este aspecto como una línea de investigación fuerte en su sistema educativo y el mejoramiento de la formación específicamente en ciencias (Cofré et al., 2010; Jakku-Sihvonen y Niemi, 2007).

Como se puede concluir de los párrafos anteriores, en Colombia, la discusión sobre la importancia de estudiar la práctica pedagógica de profesores en el campo de investigación no es un tema nuevo y hay estudios al respecto desde diferentes perspectivas (Hernández, 2001; Vasco, 1993; Zambrano, 2015) casi siempre desarrollados por grupos de investigación que pertenecen a universidades que ofrecen programas de formación de profesores. No obstante, aún no es claro el impacto que dichas investigaciones han producido en los programas de formación de profesores y en las prácticas pedagógicas en particular (Cofré et al., 2015; Gallego, Pérez y Franco, 2014; Gallego et al., 2004; García et al., 2013; Martínez y Benarroch, 2013; Misas, 2004; Torres, Badillo y Miranda, 2006; Vallejo, 2014; Zambrano, 2015). 
Se evidencia también que en estos 20 años, de manera reiterativa, los investigadores han identificado dos problemas en la formación de profesores de ciencias naturales: 1) la ausencia de apuestas curriculares de formación coherentes con las necesidades de la sociedad actual, y 2) el predominio de prácticas pedagógicas descontextualizadas y centradas en la transmisión del contenido (Alcocer y Pardo, 2012; Gallego et al., 2003; 2004; García, 2014; García et al., 2013; MEN, 2012, 2014).

En resumen, el panorama que describimos en este recorrido histórico evidencia una comunidad académicamente muy activa que ha logrado consolidar diferentes líneas de investigación a lo largo del tiempo. Sin embargo, aunque se identifica una gran producción alrededor del problema de la falta de coherencia de las prácticas, aún no se evidencia una estrategia para la transformación de las tradiciones de enseñanza en las aulas colombianas (García et al., 2013). Adicionalmente, el análisis realizado deja ver una comunidad amplia y fragmentada que se mueve entre diferentes enfoques y posturas epistemológicas.

\section{Metodología}

Este estudio se desarrolló con un enfoque cualitativo y desde una perspectiva crítica y hermenéutica, la cual permite comprender un fenómeno desde la generalidad, pero también en el detalle. Lo anterior hace posible fortalecer y consolidar un discurso válido y pertinente frente a la realidad del tema estudiado (Alvesson y Skoldberg, 2009). En este caso, el propósito es caracterizar con mayor profundidad la comunidad de investigadores en enseñanza de las ciencias analizando sus cosificaciones. Por ello, los datos recolectados provienen de la información publicada por la comunidad de investigadores en enseñanza de las ciencias en Colombia entre 2006 y 2016. Dicha información ha sido registrada por la comunidad en dos tipos de fuentes:
Fuente 1. Resultados DE INVESTIGACIÓN DOCUMENTADOS POR la comunidad en la plataforma Scienti de Colciencias. Este sistema de información tiene como objetivo principal conocer y evaluar la dinámica de la investigación en el país y guarda datos asociados con la actividad de la comunidad, tales como: quiénes son los investigadores y los grupos a los cuales pertenecen, qué tipo de productos están desarrollando, cuáles son las principales líneas de investigación, y cómo están participando las instituciones en las actividades científicas a lo largo del territorio nacional. Los datos recolectados se obtuvieron con base en tres de los aplicativos articulados en la plataforma: curriculum vitae de los investigadores (CVLAC), grupos de investigación (GrupLAC) y registros institucionales de grupos de investigación (InstituLAC). Estos aplicativos se encuentran articulados y proveen información detallada y actualizada sobre el panorama de la producción científica en un campo determinado (Tabla 1).

\section{Tabla 1. Relación de datos según las fuentes información utilizadas}

\begin{tabular}{|c|c|}
\hline Fuente & Datos recolectados \\
\hline $\begin{array}{l}\text { upos de } \\
\text { vestigación }\end{array}$ & $\begin{array}{l}\text { Periodo de confirmación. } \\
\text { Instituciones a las que pertenecen. } \\
\text { Categorización según el sistema de } \\
\text { investigación nacional de Colciencias. } \\
\text { Presencia en el territorio nacional. } \\
\text { Tipos de productos. } \\
\text { Líneas de investigación oficiales vs. las } \\
\text { que se evidencian de acuerdo con los } \\
\text { productos publicados. }\end{array}$ \\
\hline $\begin{array}{l}\text { entos de } \\
\text { vulgación }\end{array}$ & $\begin{array}{l}\text { Periodicidad. } \\
\text { Propósitos. } \\
\text { Lugares en donde se desarrollan. } \\
\text { Organización en las presentaciones. } \\
\text { Número de ponencias. } \\
\text { Perspectivas. }\end{array}$ \\
\hline
\end{tabular}

Fuente: elaboración propia.

De acuerdo con los registros obtenidos a corte del 31 de agosto de 2016, se analizaron un total de 51 grupos de investigación. Estos grupos fueron clasificados del total de grupos reportados en la plataforma de Colciencias como: grupos especia- 
lizados y grupos en educación que integran una línea en el campo.

FueNtE 2. RESULTADOS DE INVESTIGACIÓN DIVULGADOS POR LOS DOS PRINCIPALES EVENTOS NACIONALES ESPECIALIZADOS EN EL CAMPO. Se hizo un análisis de las memorias de los dos eventos más importantes realizados por la comunidad de investigadores de enseñanza de las ciencias en el país: el Congreso Nacional de Investigación en Educación en Ciencias, organizado por la Asociación Colombiana para la Investigación en Educación en Ciencia y Tecnología-Educyt, liderado por la Universidad del Valle desde el 2006, y el Congreso Internacional de Formación de Profesores, liderado por la Universidad Pedagógica Nacional y la Universidad Distrital Francisco José de Caldas a través del doctorado interinstitucional en Educación desde el año 2003. Los dos eventos mencionados se realizan cada dos años en épocas distintas y convocan a la mayoría de los integrantes de esta comunidad académica (Tabla 1).

El análisis de esta información se realizó desde la perspectiva de las comunidades de práctica propuesta por Wenger (1998) y se utilizó como apoyo el software Nvivo. Aunque Wenger hace énfasis en que la identidad, la práctica y la participación en una comunidad están íntimamente relacionadas, y resalta su carácter dual en la cotidianidad, también hace énfasis en la posibilidad de comprender la comunidad desde el estudio analítico de cada uno de ellos.

De acuerdo con lo anterior, las categorías de análisis utilizadas para esta investigación fueron:

- Identidad: está relacionada con las características que distinguen a la comunidad. Desde esta perspectiva, se analizan tres aspectos: 1) quiénes son los investigadores y cuáles son sus intereses; 2) el proceso de consolidación de los grupos de investigación, y 3) la distribución de los grupos en las instituciones educativas y en las regiones del país.

- Práctica: se considera como un "hacer algo" en un contexto histórico y social específico. En este sentido, se analizan las líneas de investigación declaradas y las que emergen de la experiencia reportada por los grupos.

- Participación: se refiere a la experiencia social de tomar parte y de intervenir activamente en una comunidad. Así, en esta categoría se analiza la participación en los dos principales eventos especializados desarrollados y avalados por la comunidad en el país.

La información obtenida en esta investigación es pública y de libre consulta. Sin embargo, hemos tenido cuidado ético con el reporte de cada una de las fuentes consultadas y con el manejo de los datos personales e institucionales.

\section{Presentación y discusión de resultados}

Con el propósito de caracterizar a la comunidad de investigadores en enseñanza de las ciencias en Colombia, en esta sección se presentan los resultados y análisis de cada una de las categorías propuestas de manera independiente. Para finalizar, se realiza una lectura holística de lo que caracteriza a la comunidad.

\section{Categoría 1. La identidad}

En esta primera sección, describimos la identidad de la comunidad a partir de los productos reportados por los grupos de investigación especializados. Adicionalmente, hacemos un análisis de los orígenes, la trayectoria y las características de los grupos oficialmente registrados por los investigadores y las instituciones a través de la plataforma ScienTI de Colciencias.

En este orden de ideas, se identifica que el grupo de investigación más antiguo que se relaciona con el campo de estudios apareció formalmente en el escenario educativo nacional el año 1978. Aunque no es un grupo especializado en la enseñanza de las ciencias, el grupo "Historia de la práctica pedagógica en Colombia" ha sido desde 1970 un colectivo 
importante para la educación en general y para la enseñanza de las disciplinas en particular. Lo anterior se evidencia en su trayectoria y en su nivel de categorización en el Sistema Nacional de Medición de Grupos. De acuerdo con Colciencias, este grupo se encuentra muy bien posicionado y para la fecha cuenta con Categoría A1. Además, está avalado por cinco de las universidades más reconocidas del país: Nacional, Pedagógica, de Antioquia, del Valle y Javeriana. Este grupo trabaja en diferentes áreas de la educación y muchos de los productos obtenidos desde sus orígenes estuvieron relacionados con la formación de profesores de ciencias.

De otro lado, el análisis del nacimiento de los grupos evidenció que la mayoría de ellos hacen presencia en el escenario académico nacional desde los años 1990 y 2000. La Figura 1 muestra la distribución de los grupos a través de los periodos de tiempo. Allí se observa un incremento significativo en el número de grupos entre los años 1990 y 2009. Zambrano (2015) propone que este crecimiento está relacionado con el incremento de los programas de posgrado en este campo, hipótesis que se valida con la información del Ministerio de Educación Nacional (MEN), que reporta un gran número de registros calificados para programas de posgrado especializados entre los años 1990 y 2000 (Figura 2). Ello evidencia que para ese periodo se planteó un escenario favorable para el fortalecimiento de la comunidad de investigadores que abrió puertas a nuevas perspectivas de trabajo.

Figura 1. Nuevos grupos de investigación conformados cada diez años

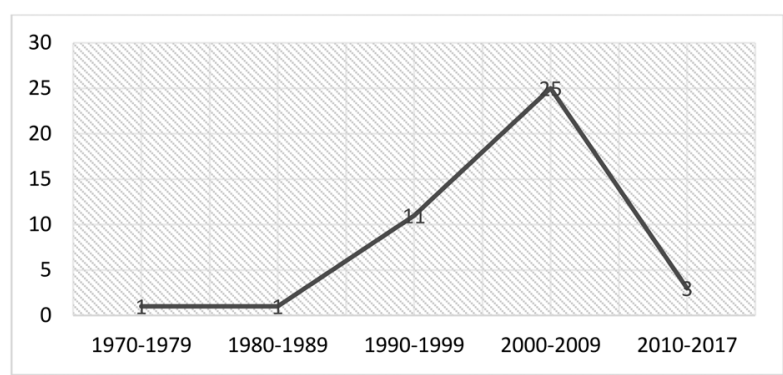

Fuente: plataforma GrupLAC.

\section{Figura 2. Programas de posgrado en educación y enseñanza de las ciencias, plataforma del MEN por periodos}

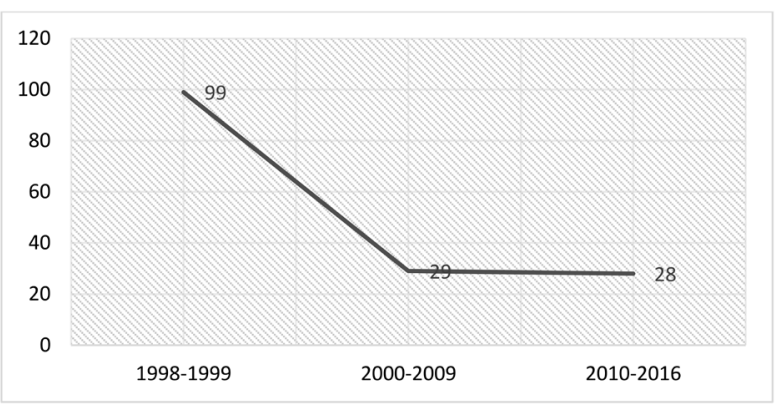

Fuente: plataforma SNIES.

En el periodo comprendido entre los años 2010 y el 2017 se identificaron en el escenario acádemico nacional tan solo tres nuevos grupos. Esto se relaciona con los esfuerzos de las instituciones educativas y de los investigadores por posicionar a sus grupos en las mejores categorías, según el sistema de clasificación de Colciencias, a través del fortalecimiento de los investigadores y el aumento en la producción de los grupos existentes, más que con la creación de nuevos grupos (Figura 4).

Por su parte, el análisis de las relaciones entre los grupos especializados, las instituciones y las regiones geográficas muestra que la Universidad Pedagógica Nacional (UPN) reportó el mayor número de grupos especializados en el campo, con un total de 11, seguida de las universidades Distrital Francisco José de Caldas, con 7 grupos, y Nacional de Colombia, con 6; mientras que, en un tercer lugar, se ubican las universidades del Valle y de Antioquia, con 4 grupos, y la de los Andes con 3 (Figura 3).

Según la información analizada, la UPN es la institución con un mayor número de grupos especializados. La razón de lo anterior es que esta universidad es pionera en programas de formación de profesores, especialmente de ciencias naturales. Actualmente, cuenta con diferentes programas de licenciatura en Biología, Química y Física y ofrece varios programas de posgrado en enseñanza de las ciencias naturales (Figura 3). 
Figura 3. Relación de grupos de investigación vs. instituciones de educación superior en Colombia. El sistema de clasificación de Colciencias

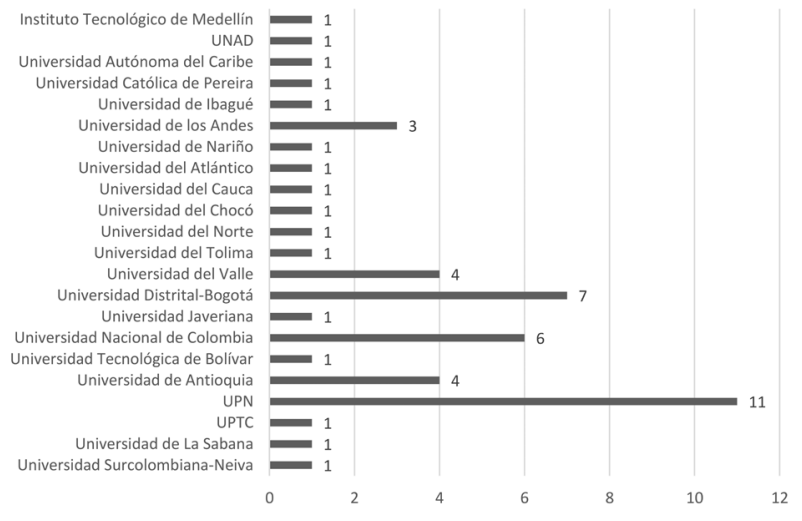

Fuente: Plataforma GrupLAC.

La clasificación propuesta por Colciencias muestra que los grupos han venido consolidando su trabajo a través del análisis que hace anualmente de su producción. Según la plataforma ScienTI, la mayoría de los grupos de investigación especializados en la enseñanza de las ciencias se encuentran clasificados en las categorías A (32,5\%), B (20\%) y C $(34,8 \%)$ (Figura 4). Los porcentajes de grupos en $A 1, A$ y B evidencian un fortalecimiento de la comunidad durante la última década.

Figura 4. Porcentaje de grupo vs. categorías

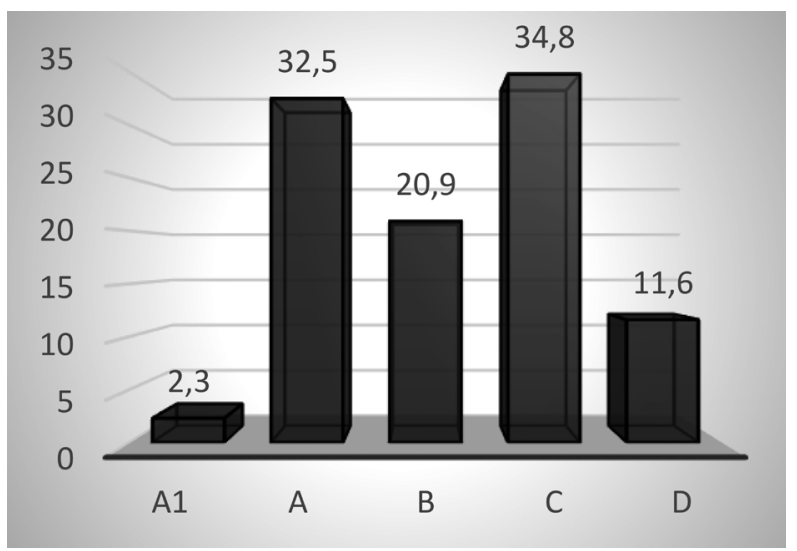

Fuente: GrupLAC.
Además de la producción científica, el sistema de categorización de Colciencias tiene en cuenta la formación de maestría y doctorado de los investigadores que hacen parte de los grupos. Al respecto, los grupos de investigación en el campo cada vez registran más miembros con nivel de maestría y doctorado, lo que es favorable a la calidad de la investigación realizada, como plantea Zambrano (2015). Esto puede estar relacionado con el crecimiento de los programas de posgrado en Colombia, así como con los escenarios de movilidad internacional que hoy por hoy se promueven en el país.

Sin embargo, la distribución de los grupos no es homogénea en el país, como se observa en la Figura 5. De acuerdo con la información obtenida, 58\% de los grupos están concentrados en la capital del país, hay representación importante en la zona oriental y se puede observar que existen departamentos en donde no se reportan grupos registrados. Esta distribución también está relacionada con el número de instituciones y programas académicos que se ofertan en el campo; según los registros del MEN, una gran parte de los programas de formación pregradual y posgradual se ofrecen en universidades que se encuentran ubicadas en Bogotá.

Figura 5. Distribución de los grupos en el territorio nacional a 2016

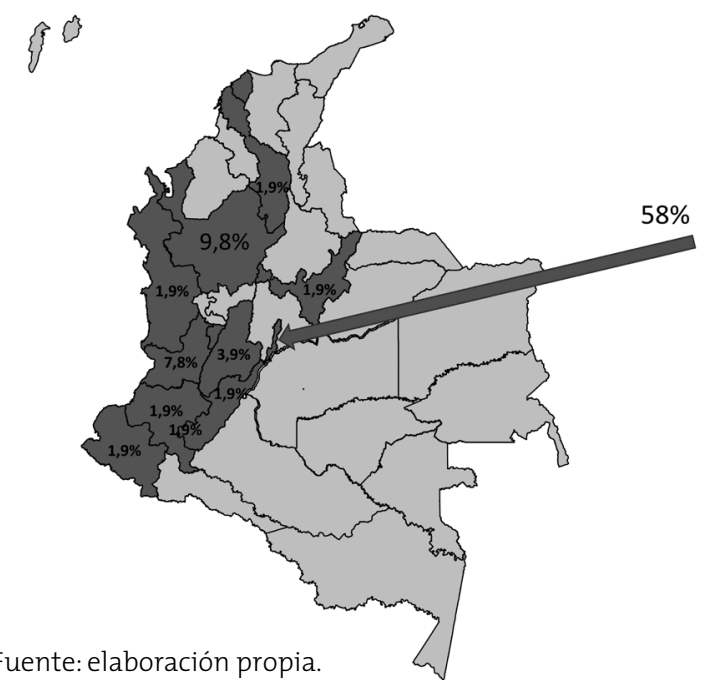


El aumento en el número de académicos y grupos de investigación dedicados a la investigación sobre educación en ciencias y la educación de los profesores de ciencias sugiere que muchas de las deficiencias detectadas en la enseñanza de la ciencia pueden ser solventadas a futuro (Cofré et al., 2015; Salinas et al., 2000). De acuerdo con la investigación de Cofre y su equipo en el 2015, Colombia, Chile y Argentina van por un buen camino en este aspecto, pues estos tres países muestran un significativo crecimiento en investigación que apunta a solucionar más adelante varias de las deficiencias identificadas en la literatura.

\section{Categoría 2. La práctica}

Desde el análisis de las cosificaciones, las líneas de investigación reportadas por los grupos representan no solo los intereses de los investigadores, sino también sus prácticas y los alcances de su trabajo. Para este fin, presentamos un análisis en tres momentos: en primer lugar, identificamos las líneas declaradas por los grupos de investigación de acuerdo con sus intereses en el aplicativo GrupLAC; en segundo lugar, presentamos las líneas que emergen de los productos de investigación reportados por los grupos y los investigadores en los aplicativos dispuestos GrupLAC y CVLAC en la última década; por último, exponemos un análisis de las relaciones entre las líneas de investigación declaradas por los grupos y las que emergen del análisis de los productos reportados por los investigadores.

El análisis de las líneas declaradas por los grupos de investigación en el aplicativo GrupLAC evidencia una gran variedad (37 líneas o temas generales). La Figura 6 muestra que las líneas con mayor número de reportes son: formación de profesores (13), enseñanza de la química (11), didáctica de las ciencias básicas y de la ingeniería (10), historia, filosofía y enseñanza de las ciencias (9), TIC y educación en ciencias (6), enseñanza de las ciencias o de las ciencias experimentales (6), conocimiento profesio- nal del profesor de ciencias (6), diversidad cultural y enseñanza de las ciencias (5), y educación, pedagogía, didáctica y gestión curricular (5).

\section{Figura 6. Líneas de investigación declaradas vs. número de grupos que las reportan}

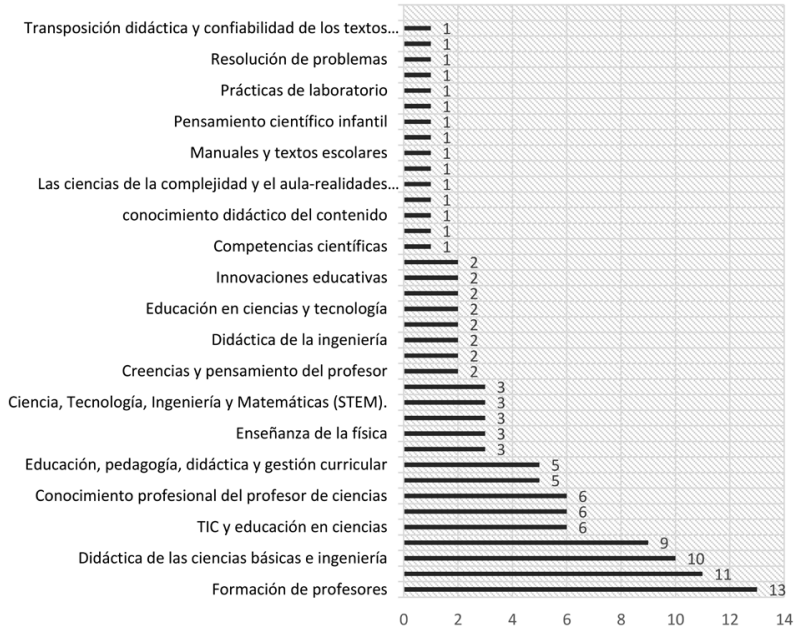

Fuente: GrupLAC

De otro lado, el análisis realizado a los productos de investigación reportados por los grupos y los investigadores en la última década (artículos, capítulos de libro, libros, etc.) permitió clasificarlos en 9 líneas (Figura 7). La mayor parte de la producción se identificó en 6 de ellas: 1) didáctica de las ciencias básicas y la ingeniería (222 productos); 2) enseñanza de las ciencias o de las ciencias experimentales (177); 3) currículo, formación profesores y conocimiento profesional del profesor de ciencias (169); 4) historia, filosofía y enseñanza de las ciencias (136); 5) conocimiento escolar y prácticas pedagógicas (84); 6) TIC y educación en ciencias (80). En contraste, las líneas que menos producción identificaron fueron: 7) educación, pedagogía y gestión curricular (40), y 8) diversidad cultural y enseñanza de las ciencias (14). También se identificaron estudios orientados a conocer el estado del arte sobre la enseñanza de la ciencia en el país, análisis que evidenció el desarrollo de 31 estados del arte en la última década. 


\section{Figura 7. Líneas emergentes por producción de los grupos en la última década}

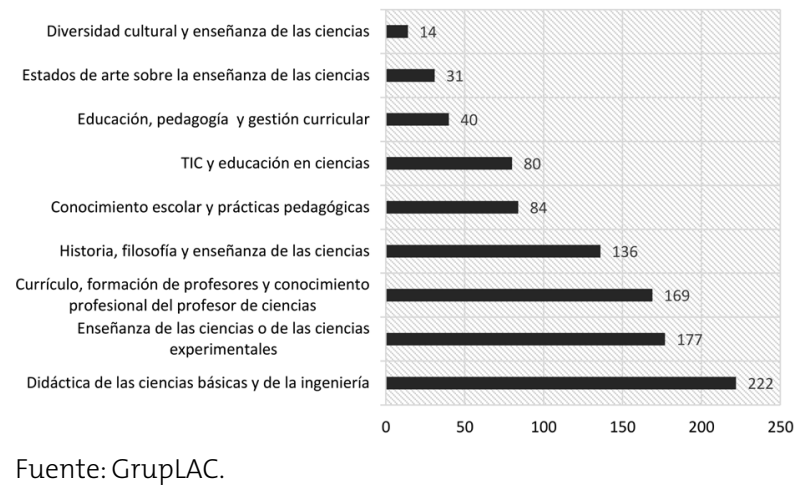

La línea de investigación en diversidad cultural y enseñanza de las ciencias en el país aparece en el escenario académico colombiano desde el año 2000 y surge como una posibilidad de integrar la perspectiva sociocultural en las prácticas pedagógicas. Esta línea brinda una oportunidad importante de desarrollar propuestas curriculares que tengan en cuenta la complejidad de la realidad.

Por último, el análisis de la relación entre las líneas declaradas por los grupos y los productos reportados en el sistema de clasificación por los investigadores evidenció una comunidad con intereses diversos. Así, las líneas de investigación que declaran los grupos en su GrupLAC abarcan un gran abanico de temas que se mueven desde lo general hasta lo particular. Al parecer estos temas surgen de las diferentes problemáticas identificadas por los investigadores desde su propia experiencia en el campo y las tendencias internacionales. Por su parte, el análisis de los productos que reportan los grupos en estos mismos aplicativos agrupó la producción (artículos, libros y capítulos de libros) en temáticas generales que responden, por un lado, a los problemas del campo y, por el otro, a dos posturas epistemológicas diferentes: la educación en ciencias y la didáctica de la ciencia.

Se evidencia que las líneas de investigación identificadas en el panorama nacional se encuen- tran articuladas con las líneas que se reportan en los principales textos científicos en el campo a nivel internacional (Gabel, 1994; Anderson, 2007; Camejo, Molina y Pablo, 2007; Furió, 1994; Gil, 1994; Siqueira, Camara, Sebastiany, Diehl y Fonseca, 2010).

Sin embargo, al estudiar cuidadosamente los alcances de los productos desarrollados desde estas dos posturas se identifica que las investigaciones apuntan a resolver problemas asociados con la práctica pedagógica. Esto supone una falta de diálogo entre los miembros de la comunidad y evidencia la necesidad de establecer puntos de convergencia y diferencias. Realizar esta conversación permitiría articular esfuerzos para fortalecer la comunidad y, por consiguiente, aportar más claramente al mejoramiento de la calidad de la educación en ciencias en el país.

Un ejemplo de esta tensión se presenta entre los textos de Zambrano y su grupo (2015), cuyo enfoque es la educación en ciencias, y el texto de Gallego et al. (2013), orientado por la didáctica de las ciencias. Ambos estudios presentan líneas de investigación, grupos e investigadores desde sus respectivos enfoques, lo que lleva a que no identifiquen y den legitimidad a la totalidad de los grupos de investigación que actualmente se encuentran activos en el campo y que hemos incluido en este estudio.

Como otro resultado destacable, se identifica que en la última década se han desarrollado 31 estados del arte en este campo de investigación, lo cual evidencia una necesidad constante de reconocer la identidad y la práctica de la comunidad. Dichos estudios también muestran de forma indirecta la articulación de las líneas a los dos enfoques mencionados. Estos resultados dan la idea de un escenario amplio, pero ambiguo internamente, en donde sus miembros aún no logran reconocer la identidad y la práctica compartida de la comunidad que conforman. 


\section{Categoría 3. La participación}

El campo de investigación en enseñanza de las ciencias en el país se caracteriza por tener una comunidad activa en el ámbito académico nacional e internacional. En la última década, esta comunidad ha logrado organizarse no solo a través de la conformación y consolidación de grupos de investigación, sino también mediante asociaciones y espacios de socialización y discusión sobre los intereses del campo. En esta categoría describimos la participación de la comunidad sobre la base de las cosificaciones de los dos eventos más importantes y reconocidos en el país: el Congreso Nacional de Investigación en Educación en Ciencias de la Asociación EDUCyT y el Congreso Internacional de Formación de Profesores de Ciencias liderado por la Universidad Pedagógica Nacional (UPN) y la Universidad Distrital Francisco José de Caldas (UDFJC).

La Asociación Colombiana para la Investigación en Educación en Ciencias y Tecnologías (EDUСуT) es una organización liderada por profesores de la Universidad del Valle y está conformada por investigadores de 12 instituciones universitarias a nivel nacional, la mayoría de ellas públicas: Universidad de Caldas, Universidad de Nariño, Universidad del Valle, UDFJC, UPN, Universidad de Antioquia, Universidad del Cauca, Universidad del Norte, Universidad Pedagógica y Tecnológica de Colombia (UPTC), Universidad Autónoma de Manizales, Universidad Surcolombiana y Universidad de La Sabana. El objetivo principal de esta organización es promover y fortalecer la comunidad en el contexto colombiano a partir del acercamiento de los investigadores en el campo. Por ello desde 2009 realiza cada dos años el Congreso Nacional de Investigación en Educación en Ciencias y Tecnología con el apoyo de las universidades que hacen parte de EDUCyT. Este espacio se ha organizado como un escenario para reflexionar, identificar y discutir las tendencias y los avances en el campo de investigación y en dos ocasiones se ha integrado con eventos internacionales, lo que les ha brindado a los investigadores participantes una mayor perspectiva de acción.
La Tabla 2 relaciona las temáticas generales y específicas establecidas por cada uno de los eventos realizados. Al analizarlas, se identifican tres temas fundamentales para la dinamización y el futuro del campo: 1) la formación de educadores en ciencias en el contexto de la investigación en el aula, 2) el sentido de la calidad en la educación en ciencias y la tecnología, y 3) la investigación en Ciencias y Tecnología en el contexto rural.

Adicionalmente, se identificó que en 2016 se incluyeron temáticas emergentes que relacionan la educación en ciencias con áreas como: el emprendimiento, la violencia, la paz, el desarrollo, la educación ambiental, el posconflicto, la educación sexual y la salud, y que hacen referencia a las necesidades más actuales del contexto sociocultural colombiano.

Las memorias del evento convocado en 2012 por EDUCyT aparecieron en la Revista EDUCYT, publicación especializada en el campo de investigación en enseñanza de las ciencias, que se edita desde el año 2010 y declara una periodicidad semestral. A pesar de lo anterior, durante el año 2016 no se encontraron registros de los números correspondientes a ese año en la página web. De otro lado, un análisis realizado a las memorias publicadas del evento evidenció una participación activa de la comunidad. Profesores investigadores y estudiantes de diferentes niveles (pregrado y posgrado) son los principales protagonistas en dicho evento. Los registros muestran un promedio de 150 ponencias presentadas para los congresos realizados entre 2012 y 2016.

Por estas razones, este congreso es un espacio importante para el acercamiento de la comunidad, en donde hay un sitio específico para la reunión de los miembros de la asociación. No obstante, llama la atención que no se encuentren registros en donde se evidencien acuerdos concretos frente a los intereses de los miembros de la comunidad. Por ejemplo, en el último encuentro realizado en el año 2016 se propuso realizar una discusión sobre los retos de la investigación en 
educación en ciencias y tecnología en el escenario de la educación rural. Sin embargo, no se hallaron en las memorias las conclusiones concretas frente a este tema particular. Lo anterior muestra una comunidad que se ha venido organizando y fortaleciendo, pero que aún no cuenta con la cohesión necesaria para obtener un mayor impacto. Es de- cir, no es suficiente con abrir los espacios para conocer lo que los otros miembros de la comunidad hacen, también es necesario abrir espacios donde se pueda llegar a acuerdos específicos respecto de las necesidades y las perspectivas futuras del campo y desde donde se pueda movilizar la generación de nuevos conocimientos.

Tabla 2. Congresos Nacionales de Educación en Ciencias y Tecnología de EDUCyT

\begin{tabular}{|c|c|c|c|}
\hline Evento & Año & Temática general & Temáticas específicas \\
\hline $\begin{array}{l}\text { I Congreso Nacional de } \\
\text { Investigación en Educación de } \\
\text { Ciencias y Tecnología } \\
\text { (Bogotá) }\end{array}$ & 2009 & $\begin{array}{l}\text { Socializar experiencias, } \\
\text { esfuerzos y problemáticas } \\
\text { en el campo de la enseñanza } \\
\text { de las ciencias naturales y la } \\
\text { tecnología. }\end{array}$ & $\begin{array}{l}\text { 1. Filosofía y enseñanza de las ciencias; } 2 \text {. Conocimiento } \\
\text { escolar y didáctica de las ciencias; } 3 \text {. Educación y las } \\
\text { TIC; políticas de educación en ciencia y tecnología en } \\
\text { Colombia; } 4 \text {. Formación de profesores y conocimiento } \\
\text { profesional, y 5. Retos y perspectivas de la enseñanza en } \\
\text { ciencias y tecnología en América Latina. }\end{array}$ \\
\hline $\begin{array}{l}\text { Seminario Internacional sobre } \\
\text { Enseñanza de las Ciencias. } \\
\text { II Congreso Nacional de } \\
\text { Investigación en Educación en } \\
\text { Ciencias y Tecnología } \\
\text { (Universidad del Valle, Cali) }\end{array}$ & 2010 & $\begin{array}{l}\text { La formación de educadores } \\
\text { en ciencias en el contexto de la } \\
\text { investigación en el aula. }\end{array}$ & \multirow{2}{*}{$\begin{array}{l}\text { 1. Multiculturalidad, etnoeducación e interculturalidad; } \\
\text { 2. Formación y evaluación de competencias científicas; } 3 \text {. } \\
\text { Problemas sobre la enseñanza, aprendizaje y evaluación } \\
\text { de las ciencias naturales; } 4 \text {. Historia y epistemología } \\
\text { en la enseñanza de las ciencias naturales, sociales } \\
\text { y matemáticas; } 5 \text {. Relación teoría-práctica en la } \\
\text { educación en ciencias: } 6 \text {. El laboratorio, la resolución } \\
\text { de problemas y las TIC; 7. Procesos de integración entre } \\
\text { ciencia, tecnología, sociedad y ambiente; } 8 \text {. Políticas de } \\
\text { educación en ciencias y tecnología en Colombia; } 9 \text {. El } \\
\text { conocimiento del profesor, el conocimiento del alumno } \\
\text { y sus interacciones; } 10 \text {. Concepción y construcción del } \\
\text { currículo en la formación de profesores en ciencias; } 11 . \\
\text { Educación en ambientes no convencionales. }\end{array}$} \\
\hline $\begin{array}{l}\text { III Congreso Nacional de } \\
\text { Investigación en Educación en } \\
\text { Ciencias y Tecnología - EDUCyT, } \\
\text { y II Congreso Iberoamericano } \\
\text { de Enseñanza de las Ciencias } \\
\text { - CIEC (Universidad de Nariño, } \\
\text { Pasto) }\end{array}$ & 2012 & $\begin{array}{l}\text { El sentido de la calidad en } \\
\text { la educación en ciencias y la } \\
\text { tecnología. }\end{array}$ & \\
\hline $\begin{array}{l}\text { IV Congreso Nacional de } \\
\text { Investigación en Educación en } \\
\text { Ciencias y Tecnología } \\
\text { (Universidad de Caldas, } \\
\text { Manizales) }\end{array}$ & 2014 & $\begin{array}{l}\text { Socializar experiencias, } \\
\text { esfuerzos y problemáticas } \\
\text { en el campo de la enseñanza } \\
\text { de las ciencias naturales y la } \\
\text { tecnología. }\end{array}$ & $\begin{array}{l}\text { 1. Formación inicial y permanente del profesorado en } \\
\text { Ciencias Naturales y Tecnología; } 2 \text {. Aspectos culturales } \\
\text { e interculturales en la enseñanza de las ciencias; } 3 \text {. } \\
\text { Currículo y enseñanza y aprendizaje de las ciencias y } \\
\text { la tecnología; } 4 \text {. La investigación en la formación de } \\
\text { profesores de ciencias; } 5 \text {. Tecnologías de la información } \\
\text { y la comunicación en la didáctica de las ciencias; } 6 \text {. } \\
\text { Enseñanza, aprendizaje y evaluación en la enseñanza de } \\
\text { las ciencias y la tecnología; } 7 \text {. Historia y epistemología } \\
\text { de la didáctica de las ciencias y la tecnología. }\end{array}$ \\
\hline $\begin{array}{l}\text { V Congreso Nacional de } \\
\text { Investigación en Educación en } \\
\text { Ciencias y Tecnología } \\
\text { (Universidad Surcolombiana, } \\
\text { Neiva) }\end{array}$ & 2016 & $\begin{array}{l}\text { Investigación en educación } \\
\text { en ciencias y tecnología: una } \\
\text { posibilidad desde lo rural. }\end{array}$ & $\begin{array}{l}\text { 1. Formación inicial y permanente del profesorado } \\
\text { en ciencias naturales y tecnología e investigación } \\
\text { en la formación de profesores de ciencias; } 2 \text {. Política } \\
\text { educativa; 3. Aspectos culturales e interculturales en } \\
\text { la enseñanza de las ciencias; } 4 \text {.Currículo, enseñanza- } \\
\text { aprendizaje y evaluación de las ciencias y la tecnología; } \\
\text { 5. Discursos metadisciplinares (historia, epistemología } \\
\text { y saberes en educación en ciencias y tecnología); } 6 \text {. } \\
\text { Temáticas emergentes (emprendimiento, violencia, } \\
\text { paz, desarrollo, educación ambiental, posconflicto, } \\
\text { educación sexual y salud). }\end{array}$ \\
\hline
\end{tabular}

Fuente: registros web de los eventos en los diferentes años. 
El segundo evento que reúne a una gran parte de la comunidad de investigadores en enseñanza de las ciencias a nivel nacional es el Congreso Internacional sobre Formación de Profesores de Ciencias. Este evento se desarrolla cada dos años desde 2003 en la ciudad de Bogotá y es organizado desde su primera versión por la revista Tecné Epistemey Didaxis: TED de la Facultad de Ciencias y Tecnología de la UPN y la Facultad de Educación de la UDFJC. Actualmente, está publicación es un espacio de divulgación académica con un importante reconocimiento latinoamericano.

Desde sus orígenes, este evento fue concebido como un espacio para: 1) reflexionar y socializar los fundamentos que orientan la formación inicial y continua del profesorado en ciencias; 2) analizar el estado de la investigación en la enseñanza de las ciencias desde la perspectiva de la didáctica de las ciencias como disciplina conceptual y metodológicamente fundamentada. Los principales campos de investigación que se trabajan en este espacio son: la formación inicial y continua del profesorado, sus concepciones acerca de las ciencias, las relaciones entre Ciencia, Tecnología, Sociedad y Ambiente (CTSA) y la evaluación.

La Tabla 3 muestra los intereses generales y las temáticas específicas que se abordaron en cada una de las versiones del congreso. Se puede evidenciar que desde su primera versión hay un interés particular por la investigación en formación inicial y permanente de profesores desde el enfoque de la didáctica de las ciencias, haciendo evidente que tiene como objetivo principal discutir sobre el estatuto epistemológico de la didáctica de las ciencias de la naturaleza.

El análisis realizado de las temáticas que se han abordado evidencia una ampliación de los intereses de investigación en el transcurso de los años. Entre los años 2003 y 2007 se propuso como temáticas centrales: la formación inicial y continua del profesorado, las concepciones acerca de las ciencias, las relaciones entre CTSA y la evaluación. En la última década se integraron otras temáticas que responden, por un lado, al interés inicial del congreso y, por el otro, a las necesidades de la educación actual. Por ejemplo, en el año 2009 se tuvieron en cuenta temáticas como: historia y epistemología de las ciencias; relaciones enseñanza-aprendizaje; estatuto científico de la enseñanza de las ciencias; y las TIC en la enseñanza de las ciencias de la naturaleza.

En el año 2011, por su parte, aparece con mayor fuerza el interés por discutir sobre el estatuto epistemológico de la didáctica de las ciencias y se declara como interés general del congreso: "La didáctica de las ciencias como disciplina conceptual y metodológicamente fundamentada". En esta oportunidad se desarrollaron conferencias centrales alrededor de este tema específico y se destacó el interés de investigación por la formación del profesorado universitario, por el conocimiento profesional y por el conocimiento didáctico del contenido. Adicionalmente, se abrió un espacio para la enseñanza de las matemáticas.

La versión que se realizó en el año 2014 presentó una comunidad mucho más consolidada, con un escenario más amplio de participación. Por un lado, se evidenció la contribución en la organización de otras instituciones nacionales, como son las universidades Santo Tomas y Autónoma de Colombia y, por el otro, el apoyo de otras instituciones internacionales, como la Universidad Pedagógica de México y la Red Latinoamericana de Didáctica de las Ciencias.

En cuanto a las temáticas que se abordaron, el análisis de las memorias del evento mostró que en el año 2014 se presentó como temática central: "La importancia de la formación del profesorado a lo largo de la vida para construir una sociedad global e incluyente". Este interés particular favoreció una reestructuración y actualización de las temáticas específicas. Dicha reestructuración no solamente obedeció a un cambio en las denominaciones, sino también a las perspectivas de trabajo en el campo. Las 13 temáticas específicas pueden identificarse en la Tabla 3. 
El evento para el año 2016 declaró como temática principal: Desafíos de la educación en ciencias para la transformación de las prácti- cas docentes. Lo anterior muestra un interés de la comunidad por transcender de la teoría a la práctica.

Tabla 3. Congreso Internacional sobre Formación de Profesores de Ciencias

\begin{tabular}{|c|c|c|c|}
\hline Evento & Año & Intereses generales & Temáticas específicas \\
\hline $\begin{array}{l}\text { I Congreso Nacional de } \\
\text { Formación de Profesores } \\
\text { de Ciencias } \\
\text { (UPN) }\end{array}$ & 2003 & \multirow{3}{*}{$\begin{array}{l}\text { Analizar los fundamentos que } \\
\text { orientan hoy la formación inicial y } \\
\text { continua del profesorado de ciencias } \\
\text { con el fin de analizar el estado de } \\
\text { la investigación en este campo, así } \\
\text { como discutir el estatuto científico } \\
\text { de la didáctica de las ciencias de la } \\
\text { naturaleza. }\end{array}$} & \multirow{3}{*}{$\begin{array}{l}\text { 1. Formación inicial y continua del profesorado, sus } \\
\text { concepciones acerca de las ciencias; } 2 \text {. Relaciones } \\
\text { Ciencia Tecnología Sociedad y Ambiente CTSA y la } \\
\text { evaluación. }\end{array}$} \\
\hline $\begin{array}{l}\text { Il Congreso Internacional } \\
\text { de Formación de } \\
\text { Profesores de Ciencias } \\
\text { (UPN y UDFJC) }\end{array}$ & 2005 & & \\
\hline $\begin{array}{l}\text { III Congreso Internacional } \\
\text { de Formación de } \\
\text { Profesores de Ciencias } \\
\text { (UPN y UDFJC) }\end{array}$ & 2007 & & \\
\hline $\begin{array}{l}\text { IV Congreso Internacional } \\
\text { de Formación de } \\
\text { Profesores de Ciencias } \\
\text { (UPN) }\end{array}$ & 2009 & $\begin{array}{l}\text { ¿Qué profesores de ciencias se } \\
\text { están formando?; ¿Desde qué } \\
\text { presupuestos epistemológicos, } \\
\text { didácticos y pedagógicos? ¿Qué } \\
\text { investigaciones se adelantan al } \\
\text { respecto? ¿Qué incidencia tiene esta } \\
\text { formación en la construcción de } \\
\text { valores y de convivencia pacífica? } \\
\text { ¿Qué versión de ciencia socializar } \\
\text { entre nuestros conciudadanos? }\end{array}$ & $\begin{array}{l}\text { 1. Formación de profesores; } 2 \text {. Relaciones CTSA;3. } \\
\text { Historia y epistemología de las ciencias; } 4 \text {. Relaciones } \\
\text { enseñanza-aprendizaje; } 5 \text {. Estatuto científico de la } \\
\text { enseñanza de las ciencias; } 6 \text {. Las TIC en la enseñanza } \\
\text { de las ciencias de la naturaleza. }\end{array}$ \\
\hline $\begin{array}{l}\text { V Congreso Internacional } \\
\text { de Formación de } \\
\text { Profesores de Ciencias } \\
\text { (UDFJC, doctorado } \\
\text { interinstitucional y } \\
\text { UNESP, Brasil) }\end{array}$ & 2011 & $\begin{array}{l}\text { La didáctica de las ciencias } \\
\text { como disciplina conceptual y } \\
\text { metodológicamente fundamentada. }\end{array}$ & $\begin{array}{l}\text { 1. Formación inicial y permanente del profesorado; } 2 \text {. } \\
\text { Formación del profesorado universitario formador } \\
\text { de formadores; } 3 \text {. Conocimiento profesional y } \\
\text { Conocimiento didáctico del contenido; } 4 \text {. Relación } \\
\text { enseñanza aprendizaje de las ciencias y las } \\
\text { matemáticas; } 5 \text {. Las TIC en la enseñanza de las ciencias } \\
\text { y las matemáticas; 6. Relaciones CTS-A; 7. Didáctica de } \\
\text { la Química. }\end{array}$ \\
\hline $\begin{array}{l}\text { VI Congreso Internacional } \\
\text { de Formación de } \\
\text { Profesores de Ciencias } \\
\text { (UPN, UDFJC, U. Santo } \\
\text { Tomas, U. Autónoma } \\
\text { de Colombia; con el } \\
\text { patrocinio de: UPN } \\
\text { de México y Red } \\
\text { Latinoamericana de } \\
\text { Didáctica de las Ciencias) }\end{array}$ & 2014 & $\begin{array}{l}\text { La Formación del profesorado a } \\
\text { lo largo de la vida: base para una } \\
\text { sociedad global e incluyente. }\end{array}$ & $\begin{array}{l}\text { 1. Enfoque CTSA: Alfabetización científica y cuestiones } \\
\text { socio científicas; } 2 \text {. Aspectos Culturales, sociales y de } \\
\text { género en la educación en ciencias; } 3 \text {. Comunicación } \\
\text { en ciencias, discurso y argumentación; } 4 \text {. } \\
\text { Conocimiento didáctico del contenido (CDC o PCK); } 5 \text {. } \\
\text { Diseño curricular y secuencias de enseñanza; docencia } \\
\text { universitaria y educación superior; } 6 \text {. Educación } \\
\text { científica en contexto; } 7 \text {. Educación en ciencias y } \\
\text { educación ambiental; } 8 \text {. Educación en ciencias y } \\
\text { TIC; 9. Educación en enseñanza de las ciencias en } \\
\text { preescolar y primaria; } 10 \text {. Evaluación en ciencias; } 11 . \\
\text { Historia y epistemología de las ciencias; } 12 \text {. Modelos y } \\
\text { modelización en ciencias. }\end{array}$ \\
\hline
\end{tabular}




\begin{tabular}{|c|c|c|c|}
\hline Evento & Año & Intereses generales & Temáticas especificas \\
\hline $\begin{array}{l}\text { VII Congreso Internacional } \\
\text { de Formación de } \\
\text { Profesores de Ciencias } \\
\text { (UPN, UDFJC y U. Sergio } \\
\text { Arboleda) }\end{array}$ & 2016 & $\begin{array}{l}\text { Desafíos de la Educación en Ciencias } \\
\text { para la transformación de las } \\
\text { prácticas docentes. }\end{array}$ & $\begin{array}{l}\text { 1. Relaciones entre investigación y enseñanza; } 2 . \\
\text { Relaciones escuela y entorno escolar; } 3 \text {. Relación } \\
\text { entre políticas y normatividad en la formación } \\
\text { del profesorado de ciencias; } 4 \text {. Relación con otras } \\
\text { áreas curriculares de la organización escolar; } 5 . \\
\text { Relaciones entre modelización, argumentación, } \\
\text { contextualización, e historia, epistemología y } \\
\text { sociología de la ciencia; } 6 \text {. Relaciones entre los } \\
\text { enfoques CTSA y Educación Ambiental; 7. Relaciones } \\
\text { entre escuela-universidad; 8. Relaciones entre las } \\
\text { TIC y nuevos escenarios didácticos; 9. Relaciones } \\
\text { entre Educación en Ciencias, diversidad inclusión, } \\
\text { multiculturalismo, interculturalidad y género. }\end{array}$ \\
\hline
\end{tabular}

Fuente: registros web de los eventos en los eventos realizados desde el año 2003. Memorias del Congreso Internacional de Formación de Profesores de Ciencias, revista TED.

Desde esta perspectiva, las temáticas plateadas para el año 2016 estuvieron orientadas a identificar los tipos de relaciones entre diferentes aspectos atinentes al contexto sociocultural de nuestro país, como se evidencia en la Tabla 3. Es decir, se evidencia una preocupación por impactar en problemas claves de la sociedad a través de la contextualización de la disciplina en el aula y fuera de ella.

La revista TED, de la Facultad de Ciencia y Tecnología de la UPN, ha publicado desde el año 2003 las memorias del Congreso Internacional de Formación de Profesores de Ciencias. Esto ha permitido llevar un registro de las investigaciones y experiencias realizadas de acuerdo con las líneas de investigación propuestas en cada versión. Vale la pena resaltar que en la publicación correspondiente al Congreso de 2016 se presentó en la editorial un análisis general de la participación de los miembros de la comunidad según las líneas que se propusieron. En este análisis se identificaron cuatro aspectos vinculados con el desarrollo del congreso: 1) la relación entre el número de trabajos presentados (401) en la convocatoria y el número de trabajo aceptados por los evaluadores (237); 2) el porcentaje de trabajos reportados por cada una de las temáticas establecidas; 3) las temáticas en donde se evidencia una mayor participación de la comunidad en el país; y, por último, 4) las temáticas en donde se considera que debe dedicarse más atención y esfuerzos (Martínez, 2016).

Martínez (2016) expresa que en esta última versión del Congreso se destacaron trabajos orientados a pensar en la articulación de las problemáticas ambientales con la educación en ciencias y en la importancia de generar propuestas formativas para profesores que reconozcan los contextos socioculturales que caracterizan las dinámicas educativas en América Latina. Adicionalmente, plantea la necesidad de integrar la producción de conocimiento en el campo con la construcción de las políticas públicas.

El análisis de los dos eventos muestra una comunidad muy activa en términos de participación. Los resultados presentados evidencian un gran interés por comunicar y compartir, desde cada una de las posturas evidenciadas, las reflexiones y resultados obtenidos de sus investigaciones. Así, esta participación activa facilita la identificación de problemáticas, soluciones y tendencias futuras. Sin embargo, para alcanzar transformaciones significativas en la enseñanza y el aprendizaje del campo es necesario promover más colaboraciones entre las instituciones y grupos de investigación. Sin duda, una mayor articulación entre sus miembros y sus líneas epistemológicas tendría un mayor impacto en la realidad de la práctica. 


\section{A manera de conclusión}

El análisis de las cosificaciones desarrolladas por la comunidad de investigadores en enseñanza de las ciencias en Colombia durante la última década mostró una comunidad robusta que se viene consolidando desde hace aproximadamente 30 años, conformada por 51 grupos de investigación especializados en el campo. La mayoría de los grupos identificados pertenecen a instituciones universitarias con programas de formación de profesores. El 58\% de los grupos pertenecen a instituciones universitarias ubicadas en la capital del país, lo cual puede llevar a una monopolización de la investigación.

De acuerdo con el sistema de clasificación de Colciencias, en los últimos años los grupos de investigación se han posicionado en un nivel alto. Es decir, el 32\% de ellos se encuentran clasificados en categoría A y un $20 \%$ en B. La gran mayoría de la producción registrada por los grupos está articulada con los programas de formación pregradual y posgradual que se ofertan en las diferentes universidades del país.

La práctica en esta comunidad se construye sobre una gran variedad de intereses que surgen desde la experiencia y la postura epistemológica que tienen los investigadores y los grupos. El análisis realizado identifica el abordaje de los problemas propios del campo de investigación desde dos perspectivas: la educación en ciencias y la didáctica de las ciencias. Estas perspectivas orientan la producción de los investigadores, directa o indirectamente; incluso se han desarrollado producciones orientadas a establecer los estatutos epistemológicos de estos enfoques.
Los productos analizados evidencian que desde estas dos perspectivas se pretende resolver los mismos tipos de problemas; por ejemplo, dificultades relacionadas con la práctica pedagógica. Esto muestra la necesidad de realizar un acercamiento entre estas dos posturas, identificar puntos de encuentro y hallar respuestas contundentes a los problemas identificados, que han sido recurrentes por más de 20 años en Colombia. La negociación de este tipo de significados dentro de la comunidad favorecerá no solo la práctica de la comunidad, sino también el mejoramiento de la educación en ciencias en nuestro país.

Los investigadores participan de la comunidad a través de la presentación de sus productos en revistas y eventos nacionales e internacionales. En los dos eventos nacionales estudiados se evidenció que las participaciones se limitan a presentar sus trabajos y recibir comentarios al respecto. No se muestran productos que retomen los acuerdos a los cuales llegó la comunidad en los diferentes espacios de discusión propuestos por los eventos. Es decir, aunque hay escenarios de socialización, no es evidente un diálogo colectivo que identifique los acuerdos respecto de las necesidades del campo de investigación. Una consecuencia de esta falta de comunicación es que la comunidad se mantiene investigando las mismas temáticas sin conseguir mayores transformaciones de la realidad de la educación en ciencias en Colombia, en la práctica directa de aula en todos los niveles educativos. Es decir, para impactar a mediano y corto plazo la educación en ciencias en Colombia se necesitan proyectos nacionales que se realicen de forma colaborativa entre las instituciones y los grupos de investigación. 
ISSN 0123-1294 | e-ISSN 2027-5358 | Educ.Educ. Vol. 23. No.1 | Febrero-abril de 2020 | pp. 47-68.

Universidad de La Sabana | Facultad de Educación

\section{Referencias}

Anderson, C. W. (2007). Perspectives on Science Learning. En S. K. Abell y N. G. Lederman (eds.), Handbook on Research on Science Education (pp. 3-30). Mahwah, NJ: Lawrence Erlbaum.

Alcocer, M. y Pardo, J. (2012). Estudio de las concepciones ciencia, química, enseñanza y aprendizaje de profesores de ciencias en formacion inicial. Bogotá: Universidad Pedagógica Nacional.

Alvesson, M.y Skoldberg, K. (2009). Reflexive Methodology. Londres: Sage.

Badillo, R., Torres, A. y Miranda, R. (2002). Historia de la didáctica de las ciencias: un campo de investigacion. Tecné Episteme y Didaxis: TED, 12. https://doi.org/10.17227/ted.num12-5970

Barrera, F., Maldonado, D. y Rodríguez, C. (2012). Calidad de la educación básica y media en Colombia: Diagnóstico y propuestas. Documentos de Trabajo, 126, Universidad del Rosario. https://ideas.repec.org/p/ col/oooog2/010078.html

Camejo, C., Alberto, C., Molina, R. y Pablo, P. (2007). Las tendencias de la didáctica de las ciencias naturales en el Siglo XXI. Varona, 44 (enero-junio), 34-41.

Cofré, H. et al. (2010). La educacion cientifica en Chile: Debilidades de la enseñanza y futuros desafíos de la educación de profesores de ciencia. Estudios Pedagógicos, 36(2), 279-293. https://www.redaly c.org/ pdf/3606/360635564007.pdf

Cofré, H. et al. (2015). Science Teacher Education in South America: The Case of Argentina, Colombia and Chile. Journal of Science Teacher Education, 26(1), 45-63. https://doi.org/10.1007/s10972-015-9420-9

Echeverri, G. (2010). La escuela y el maestro: movimientos y acción situada en tensión. Escuela, Memoria y Movimiento Pedagógico en Colombia, 55, 5-36.

Elliott, J. (1993). El cambio educativo desde la investigación-acción Madrid: Morata.

Furió, C. J. (1994). Tendencias actuales en la formación del profesorado de ciencias. Enseñanza de las Ciencias, 12(2), 188-199. https://www.raco.cat/index.php/Ensenanza/article/view/21357

Gabel, L. (1994). Handbook of Research on Science Teaching and Learning. Nueva York: McMillan.

Gallego, R., Pérez, R.y Franco, R. (2014). Transformaciones de las concepciones en la formación inicial de profesores de química. Bogotá: Universidad Pedagógica Nacional, CIUP.

Gallego, R., Pérez, R., Gallego, A. y Figueroa, R. (2013). Historia social de la educación en ciencias. Segunda mitad del siglo XX: Una constrastación. Ciência \& Educação (Bauru), 19,4,995-1012. https://doi.org/10.1590/S151673132013000400013

Gallego, R., Pérez, R., Gallego, A., Torres de Gallego, L. y Amador, R. (2003). La formación inicial de profesores de ciencias en Colombia. Contrastación de fundamentos. Bogotá: Universidad Pedagógica Nacional. 
Gallego Badillo, R., Pérez Miranda, R., Gallego, T. de y Nery Torres, L. (2004). Formación inicial de profesores de ciencias en Colombia: un estudio a partir de programas acreditados. Ciência \& Educação (Bauru), 10, 219234. https://doi.org/10.1590/S1516-73132004000200006

García, J. (2014). A propósito de los resultados de las pruebas PISA en Colombia. Uni-Pluriversidad, 14(1), editorial. https://aprendeenlinea.udea.edu.co/revistas/index.php/unip/article/view/18599

García, S., Maldonado, D., Perry, G., Rodríguez, C.y Saavedra, J. (2013). Tras la excelencia docente: ¿Cómo mejorar la calidad de la educación para todos los colombianos? Bogotá: Fundación Compartir.

Gil, D. (1994). Diez años de investigación en didáctica de las ciencias: realizaciones y perspectivas. Enseñanza de las Ciencias, 12(2), 154-164. https://core.ac.uk/download/pdf/38990362.pdf

Gil Pérez, D., Carrascosa Alís, J. y Martínez Terrades, F. (1999). El surgimiento de la didáctica de las ciencias como campo específico de conocimientos. Revista Educación y Pedagogía, 11(25), 56. https://aprendeenlinea. udea.edu.co/revistas/index.php/revistaeyp/article/view/5859

Hernández, C. (2001). Aproximación a un estado del arte de la enseñanza de las ciencias en Colombia. Bogotá: Colciencias, Icfes, socolpe.

Icfes - Instituto Colombiano para el Fomento de la Educación Superior (2013). Módulo de Pensamiento Científico: Ciencias Físicas, Saber Pro 2013-2.

Jakku-Sihvonen, J. y Niemi, H. (2007). Research-based teacher education in Finland: Reflections by Finnish teacher educators. Helsinki, Finland: Finish Educational Research Association.

López,A(2006).Educaciónenciencias naturales.Visiónactualizadadelcampo.Revista Mexicana delnvestigación Educativa, 11(30), 721-739. http://www.scielo.org.mx/scielo.php?script=sci_arttext\&pid=\$1405-66662006000300721

Martínez, J. y Benarroch, A. (2013). Concepciones y creencias sobre ciencia, aprendizaje y enseñanza de profesores universitarios de ciencias. Educación en Ciencias, 8, 24-41. http://dialnet.unirioja.es/servlet/ articulo?codigo $=4462806$

Martínez, L. (2016). Porcentajes de trabajos por ejes. Memorias del VII Congreso Internacional de Formación de Profesores de Ciencias. Tecné, Epistemey Didaxis TED.

MEN - Ministerio de Educación Nacional (2012). Colombia: qué y cómo mejorar a partir de la prueba PISA. Al Tablero, 1. http://www.mineducacion.gov.co/1621/article-162392.html

MEN - Ministerio de Educación Nacional (2004). Estándares de competencias de ciencias naturales y ciencias sociales. Bogotá.

Misas, G. (2004). La educación superior en Colombia: análisis y estrategias para su desarrollo. Bogotá: Universidad Nacional de Colombia. 
ISSN 0123-1294 | e-ISSN 2027-5358 | Educ.Educ. Vol. 23. No.1 | Febrero-abril de 2020 | pp. 47-68.

Universidad de La Sabana | Facultad de Educación

Porlán A., R. (1985). Pasado, presente y futuro. Debates, 16, 175-185.

Salinas, J. et al. (2000). La formación de los profesores de ciencias en iberoamérica. Revista Iberoamericana, 24, 163-187. https://www.researchgate.net/publication/39152859_La_formacion_de_los_profesores_de_ ciencias_en_iberoamerica

Siqueira, J., Camara, M., Sebastiany, A., Diehl, I.y Fonseca, M. (2010). La práctica docente declarada y realizada por profesores en formación inicial. Revista Electrónica de Enseñanza de las Ciencias, 9, 1-17. http://reec.uvigo. es/volumenes/volumeng/ART1_VOL9_N1.pdf

Soussan, G. (2003). Enseñar las ciencias experimentales. Didáctica y formación. Santiago de Chile: Unesco.

Stenhouse, L. (1987). La investigación como base de la enseñanza. Madrid: Morata.

Torres, A., Badillo, R. y Miranda, R. (2006). ¿Qué versión de ciencia se enseña en el aula? Educación y Educadores, 9(1) 105-116. https://educacionyeducadores.unisabana.edu.co/index.php/eye/article/view/650

Vallejo, S. (2014). Las competencias cientificas en la politica educativa colombiana: Privilegio de la perspectiva parcial al estudiar su ensamblaje desde los Estudios Sociales de la Ciencia. Bogotá: Universidad Nacional de Colombia.

Vasco, C. (1993). Enseñanza de las ciencias. Perspectivas para una escuela del mañana. Bogotá: Asociación Colombia para el Avance de la Ciencia.

Viennot, L. (1997). Former en didactique, former sur le contenu? Didaskalia, 10, 75-96. https://doi. org/10.4267/2042/23799

Wenger, E. (1998). Communities of practice: learning, meaning, and identify. Cambridge: University of Cambridge Press.

Zambrano, A. (2003). Educación y formación del pensamiento científico: Cátedra ICFES Agustín Nieto Caballero. Bogotá: Icfes.

Zambrano, C. (2015). Estatuto epistemologico de la investigación en educación en ciencias 2000-2011. Cali: Universidad del Valle.

Zambrano,A., Salazar,T.,Candela, B.y Villa, L. (2013). Las líneas de investigación en educación en ciencias en Colombia.Revista EDUCYT,7(junio-diciembre). http://bibliotecadigital.univalle.edu.co/bitstream/10893/8666/1/ Las\%2oLineas\%20De\%2olnvestigacion.pdf

Zambrano, C., Viáfara, R. y Marín, M. (2008). Estudio curricular sobre la enseñanza de las ciencias naturales y la educación ambiental en instituciones educativas de Barranquilla. Studiositas, 3(2), 5-21. https://core. ac.uk/download/pdf/71891447.pdf 